Забориева Т. И., Гомбоев Б. О. Производственные, инфраструктурные и научнопроизводственные основания устойчивого развития Иркутской области

УДК 911.3:33

DOI 10.18101/2587-7143-2019-1-45-54

\title{
ПРОИЗВОДСТВЕННЫЕ, ИНФРАСТРУКТУРНЫЕ И НАУЧНО-ПРОИЗВОДСТВЕННЫЕ ОСНОВАНИЯ УСТОЙЧИВОГО РАЗВИТИЯ ИРКУТСКОЙ ОБЛАСТИ
}

Т. И. Заборцева, Б. О. Гомбоев

(C) Заборцева Татьяна Ивановна

д.г.н., заведующая лабораторией экономической и социальной географии, профессор кафедры географии, картографии, геосистемных технологий;

Институт географии СО РАН, Иркутский государственный университет; 664033, г. Иркутск, ул. Уланбаторская, 1

E-mail: zabti@irigs.irk.ru

\section{(ㄱ) Гомбоев Баир Октябрьевич}

д.г.н., главный научный сотрудник, заведующий кафедрой географии и геоэкологии; Байкальский институт природопользования СО РАН, Бурятский государственный университет; 670047, г. Улан-Удэ, ул. Сахьяновой, 8

E-mail: bgom@binm.ru

\section{Для цитирования:}

Забориева Т. И., Гомбоев Б. О. Производственные, инфраструктурные и научно-производственные основания устойчивого развития Иркутской области // Вестник Бурятского государственного университета. Биология, география. 2019. № 1. C. $45-54$.

В статье рассмотрены производственные, инфраструктурные и научнопроизводственные основания устойчивого развития Иркутской области, как одной из опорных экономических территорий Сибири. Показано, что конкурентные преимущества Иркутской области заключаются в наличии крупных запасов природных ресурсов (газ, нефть, редкие металлы, железная руда, калийные соли, апатит и др., лесные, энергетические), срединном транспортно-географическом положении в России на Транссибе, относительной близости к странам Восточной и Юго-Восточной Азии. Определено, что одним из основных приоритетов развития Иркутской области являются комплексное развитие перерабатывающей промышленности на основе использования природных ресурсов, экологический туризм. Сложившаяся научно-образовательная база Иркутской области (институты Иркутского научного центра СО РАН, более 20 государственных и коммерческих ВУЗов, возрождающаяся сеть средних специальных обучающих образовательных организаций и др.) призваны обеспечивать современный уровень развития конкретных программ и технических проектов, продвигая идеологию устойчивого развития. 
Рассмотрены Цели Устойчивого Развития ООН 2030 применительно к программам социально-экономического развития Иркутской области и показаны предпосылки их реализации на рассматриваемой территории.

Ключевые слова: природно-ресурсный потенциал, индустриальное развитие, транспортно-коммуникационная функция, цели устойчивого развития, научнопроизводственная деятельность.

\section{Введение}

Иркутская область - одна из опорных экономических территорий Сибири и индустриальных субъектов Восточной Сибири, численность населения 2,4 млн чел. (1,6 \% от населения страны на 01.01.2018 г.), площадь - 774,8 тыс. кв. км (4,6 \% площади РФ). Для Иркутской области в региональной Стратегии федерального Правительства по развитию Восточной Сибири в числе конкурентных преимуществ обозначены крупные сырьевые ресурсы. Территория отличается высоким природно-ресурсным потенциалом, в том числе минерально-сырьевым (золото, железная руда, каменный уголь, углеводородное сырье и др.), гидроэнергетическим, а также лесными ресурсами (3 место среди регионов России), мирового статуса рекреационными ресурсами (оз. Байкал и центральная экологическая зона Байкальской природной территории. Одним из основных приоритетов развития - комплексное развитие перерабатывающей промышленности на основе использования природных ресурсов (География Сибири.., 2014).

Цели и задачи. Целью настоящей статьи является анализ производственных, инфраструктурных и научно-производственных оснований устойчивого развития Иркутской области. В соответствии с указанной целью определены следующие задачи: краткая характеристика природно-ресурсных оснований развития области; оценка энергетической и перерабатывающей отраслей; анализ крупных инвестиционных проектов на рассматриваемой территории; характеристика создания и развития инвестиционного производства - технопарком в соответствии с ЦУР ООН 2030.

Материалы и методы. Базовым материалом статьи являются статистические данные по направлениям рассмотрения проблем в статье, литературные источники, материалы исследований авторов, программные и проектные данные государственных и частных организаций и предприятий. Основным методом исследований по рассматриваемым вопросам является комплексный экономико-географический метод, а также статистический и расчетный методы с использованием картографического метода.

Результаты и их обсуждение. За прошедшие годы на рассматриваемой территории произошли изменения в межрегиональном соотношении выработки электроэнергии, конкретно - снижение доли Иркутской области, обусловленное: a) вводом на проектную мощность Богучанской ГЭС (Красноярский край, в 2015 г);.б) сокращением из-за продолжительного периода маловодья в бассейне Байкала производства электроэнергии (с 23,2 до 15,3\% в общесибирских показателях) (табл.1). В списке крупнейших электростанций Сибири с установленной электрической мощностью более 1000 МВт три объекта - в Иркутской области (вторая позиция по установленной мощности и годовой выработке в регионе). 
Забориева Т. И., Гомбоев Б. О. Производственные, инфраструктурные и научнопроизводственные основания устойчивого развития Иркутской области

Доля Восточной Сибири, в том числе в Иркутской области, в сибирском макрорегионе стабильно высока как по показателю производства электроэнергии (до 2005 г. в среднем 53,5 \%, с 2010 г. - 48,5 \%), так и по объему ее потребления - в среднем $46,4 \%$. Крупные потребители продукции энергетики в производственном секторе - преимущественно предприятия цветной металлургии Красноярского края и Иркутской области (холдинг «РУСАЛ»). Отрицательная динамика потребления электроэнергии в этих регионах - уход с рынка предприятий обрабатывающей промышленности, продукция которых не выдержала конкуренции в рыночных условиях или оказалась невостребованной на российском рынке.

Таблица 1

Производство и потребление электроэнергии в Восточной Сибири

\begin{tabular}{|l|c|c|c|c|c|c|c|}
\hline & $\mathbf{1 9 9 0}$ & $\mathbf{1 9 9 5}$ & $\mathbf{2 0 0 0}$ & $\mathbf{2 0 0 5}$ & $\mathbf{2 0 1 0}$ & $\mathbf{2 0 1 5}$ & $\mathbf{2 0 1 6}$ \\
\hline $\begin{array}{l}\text { Сибирь } \\
\text { (млрд. кВт-ч) }\end{array}$ & $289 / 281,1$ & $254,3 / 237,2$ & $258,6 / 247,8$ & $278 / 276,3$ & $306,2 / 308,8$ & $322,1 / 314,7$ & $328 / 319,8$ \\
\hline $\begin{array}{l}\text { Доля Сибири в } \\
\text { производстве } \\
\text { электроэнергии в } \\
\text { России (\%) }\end{array}$ & $26,7 / 26,1$ & $29,6 / 28,2$ & $29,5 / 28,7$ & $29,2 / 29,4$ & $29,5 / 30,3$ & $30,2 / 29,7$ & $30,1 / 29,7$ \\
\hline $\begin{array}{l}\text { Доля Восточной } \\
\text { Сибири в Сибири } \\
\text { (\%), в том числе: }\end{array}$ & $\mathbf{5 1 , 5 / 4 5 , 8}$ & $\mathbf{5 6 , 2 / 5 1 , 0}$ & $\mathbf{5 4 , 0 / 4 9 , 7}$ & $\mathbf{5 1 , 7 / 4 6 , 1}$ & $\mathbf{4 8 , 8 / 4 4 , 9}$ & $\mathbf{4 7 , 8 / 4 3 , 4}$ & $\mathbf{4 8 , 8 / 4 3 , 7}$ \\
\hline Республика Бурятия & $1,6 / 2,1$ & $1,3 / 2,1$ & $1,2 / 2,0$ & $1,4 / 2,0$ & $1,6 / 1,7$ & $1,8 / 1,8$ & $1,7 / 1,8$ \\
\hline Республика Тыва & $0,0 / 0,2$ & $0,0 / 0,3$ & $0,0 / 0,2$ & $0,0 / 0,3$ & $0,0 / 0,2$ & $0,0 / 0,3$ & $0,0 / 0,3$ \\
\hline Республика Хакасия & $\begin{array}{l}7,6 / \text { нет } \\
\text { данных }\end{array}$ & $10,8 / 3,8$ & $9,9 / 4,0$ & $8,9 / 4,3$ & $4,4 / 5,6$ & $7,2 / 5,2$ & $9,0 / 5,4$ \\
\hline Забайкальский край & $1,2 / 2,1$ & $1,8 / 2,9$ & $2,3 / 2,7$ & $2,2 / 2,4$ & $2,2 / 2,5$ & $2,3 / 2,5$ & $2,2 / 2,5$ \\
\hline Красноярский край & $17,9 / 21,7$ & $18,9 / 19,9$ & $19,7 / 19,7$ & $18,8 / 18,1$ & $20,2 / 17,3$ & $21,4 / 16,9$ & $20,6 / 16,9$ \\
\hline Иркутская область & $\mathbf{2 3 , 2 / 1 9 , 7}$ & $\mathbf{2 3 , 4 / 2 2 , 0}$ & $\mathbf{2 0 , 9 / 2 1 , 1}$ & $\mathbf{2 0 , 4 / 1 9 , 0}$ & $\mathbf{2 0 , 4 / 1 7 , 6}$ & $\mathbf{1 5 , 1 / 1 6 , 7}$ & $\mathbf{1 5 , 3 / 1 6 , 8}$ \\
\hline
\end{tabular}

Примечание: числитель - производство, знаменатель - потребление электроэнергии.

Составлено по: Регионы России.., 2000, 2012, 2017;

http://www.gks.ru/free_doc/new_site/business/prom/el_potr.htm

В Иркутской области отмечается увеличение объемов добычи нефти до 17,7 млн т, что связано со стимуляцией отрасли через предоставление недропользователям льгот по экспортной пошлине трем работающим компаниям: «Верхнечонскнефтегаз» (дочернее общество нефтяной компании - НК «Роснефть»), ООО «Иркутская нефтяная компания» (ИНК) и НК «Дулисьма» (рис.1). Построенный нефтепровод Куюмба (Красноярский край) - Тайшет (Иркутская область) в 2016 г. стал связующим звеном между Юрубчено-Тохомским и Куюмбинским месторождениями в Эвенкии и трубопроводной системой Восточная Сибирь - Тихий океан (ВСТО).

На территории Иркутской области работает дочерняя компания ПАО «Газпром» - ООО «Газпром добыча Иркутск». Основным и наиболее крупным проектом 
компании является подготовка и эксплуатация Ковыктинского газоконденсатного месторождения с последующим присоединением к магистральному планируемому газопроводу «Сила Сибири» (поставки в Китай, газификации субъектов и Восточной Сибири).

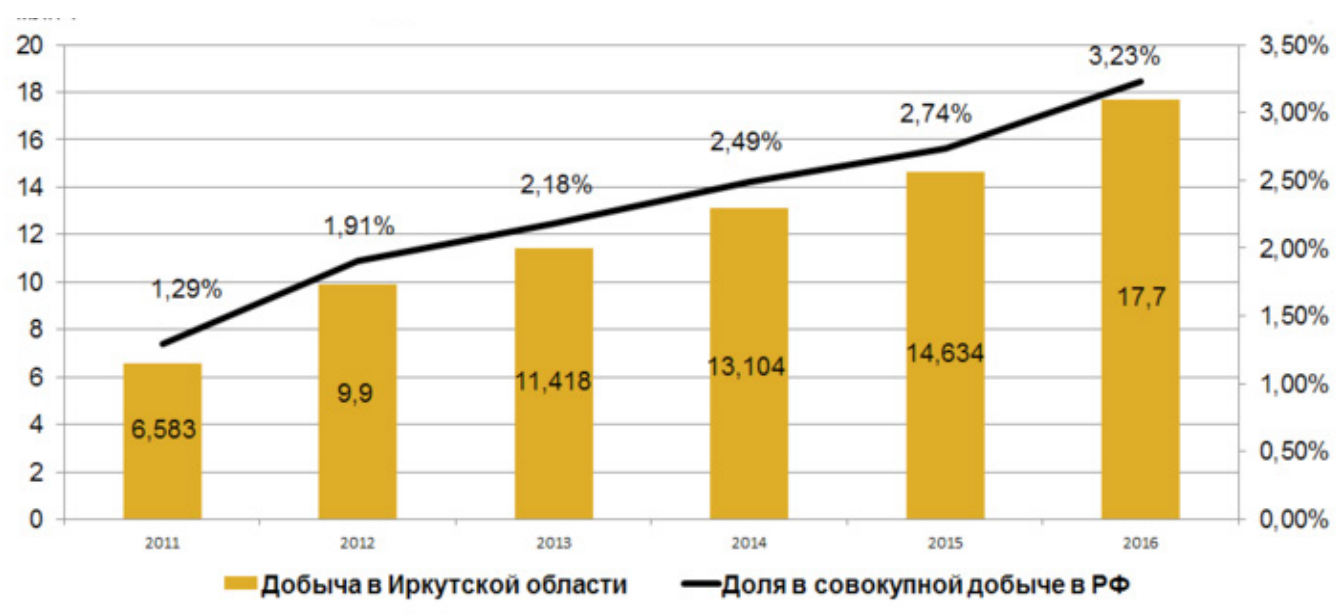

Источник: РА "Эксперт"

Рис. 1. Динамика добычи нефти в Иркутской области (Нефтегазовый..., 2018).

Иркутскую область отличает нефтеперерабатывающий и химический комплексы, сложившиеся в плановый период экономики. Производство поваренной соли - более 1 млн т/ год отличается самой низкой в стране себестоимостью (в г. Усолье-Сибирском - крупнейший в России комбинат «Сибсоль», который закрывает $2 / 3$ российского пищевого рынка, по химическому составу и вкусовым качествам усольская соль считается одной из лучших в мире).

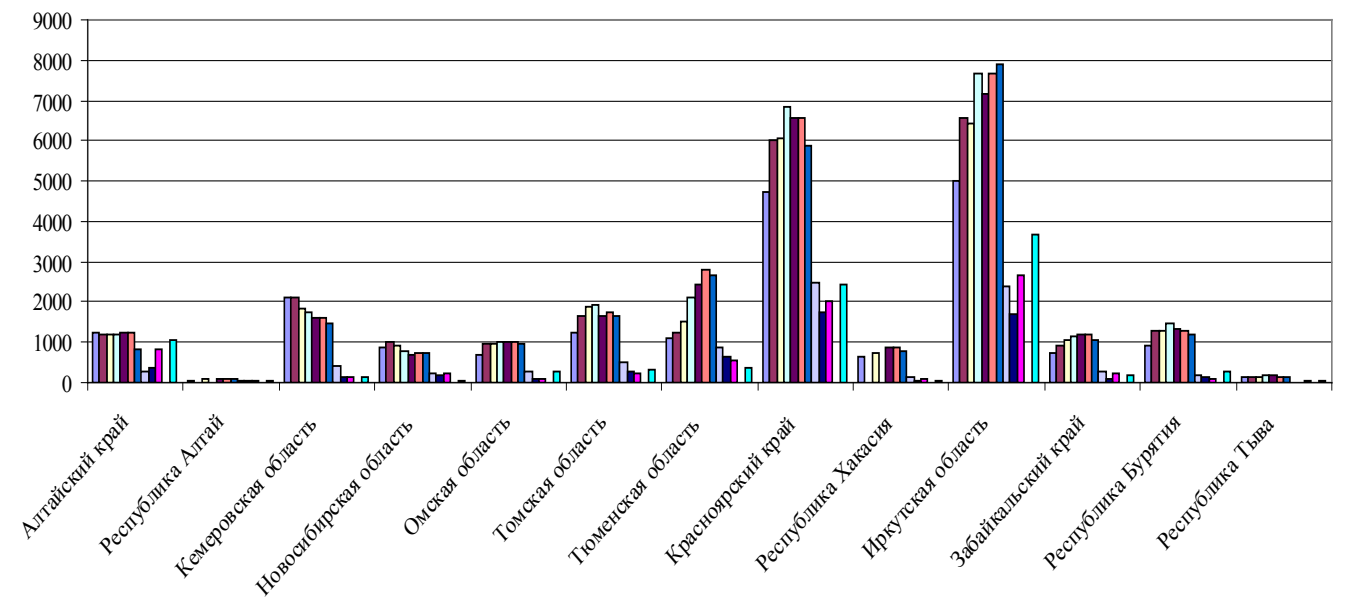

$\square 1960 \square 1965 \square 1970 \square 1975 \square 1980 \square 1985 \square 1990 \square 1995 \square 2000 \square 2005 \square 2010 \square 2015$

Рис. 2. Производство деловой древесины (тыс м³/год, автор Макаренко Е. Л.). Составлено по: Народное хозяйство РСФСР..., 1966, 1978, 1986, 1988; Регионы России.., 2000, 2012, 2016. 
Забориева Т. И., Гомбоев Б. О. Производственные, инфраструктурные и научнопроизводственные основания устойчивого развития Иркутской области

Одним из лидеров золотодобычи в России является Восточная Сибирь $39,1 \%$ от суммарной добычи в стране, при этом доля Иркутская области 9,4 \% от общероссийской и $1 / 4$ - восточносибирской добычи (лидер - Красноярский край) (Ипполитова, 2018). В Иркутской области в 1,5 раза увеличилась добыча золота за период 2007-2015 гг., достигнув отметки 22 т.

На территории области производится более четверти всего выпускаемого в России алюминия. Одни из ведущих предприятий российской алюминиевой отрасли, в Восточной Сибири - Иркутский алюминиевый завод (ИркАЗ, мощность 400 тыс.т) и Братский АЗ (БрАЗ - 30\% всего объема отечественного алюминия и 4\% мирового производства металла, производительность - более 1 млн т с 2016 г.). Завод экспортирует продукция во многие страны Европы, ЮгоВосточной Азии, в том числе в Корею, Японию, страны СНГ. В перспективе выход на производственную мощность Тайшетского алюминиевого завода.

Ежегодный объем заготовки в области - более 30 млн м³ древесины, здесь расположены гиганты российской лесной промышленности по комплексной безотходной переработке древесины - Братский и Усть-Илимский комплексы. По производству деловой древесины, пиломатериалов Иркутская область лидирует среди регионов Сибири (рис. 2).

Одна из ключевых функций Иркутской области в территориальном разделении труда (ТРТ), обусловленная срединным географическим положением в северной Евразии - транспортно-коммуникационная. Иркутская область, как и Республика Бурятия повышают статус взаимоотношений (региональный, межрегиональный, межгосударственный) по мере реализации продвигаемого Глобального проекта «Один пояс - Один путь» (Шелковый путь) на основе коренной модернизации Транссибирской железной дороги

Согласно экспертным оценкам почти двукратно увеличится и туристический поток на побережье озера Байкал (среднегодовой оценивается в 2,3 млн чел.), что будет способствовать проявлению мультипликационного эффекта в сопутствующих отраслях на территории области и республики (Зона транссиба.., 2016;. Экономический коридор.., 2018). Активно формируются новые туристические продукты («Байкальское кольцо», «Города азиатской России Транссиба» и др.) соединяющие Байкальский регион и Дальний Восток России.

Перспективные направления сотрудничества будут определяться развитием существующих крупных инвестиционных проектов (ВСТО), а также планируемых («Сила Сибири»), что соответствует целям устойчивого развития (ЦУР $8,9,10)$. Согласно расчетным данным, планируемые налоговые поступления в консолидированный бюджет Иркутской области только от топливноэнергетического комплекса возрастут почти шестикратно с 2010 г. к 2030, в 1,5 раза за последний долгосрочный 10-летний период (с 9,8 в 2010 г. до 57 млрд руб./год к 2030), что будет способствовать улучшению качества жизни местного населения. (ЦУР: 11 направление).

Программы, принятые в последнее десятилетие XXI века, будут способствовать более тесному взаимодействию регионов Восточной Сибири с Приморьем и Хабаровским краем. 
Продвигаемое отечественное направление устойчивого развития в формате инновационного производства - технопарки (ЦУР: 9. Создание прочной инфраструктуры, содействие обеспечению всеохватной и устойчивой индустриализации и внедрению инноваций). В России действует или находится в стадии формирования более 120 технопарков, 2 из них - в Иркутской области (табл. 2).

Таблица 2

Технопарки Иркутской области

\begin{tabular}{|c|c|}
\hline Город & Специализация технопарка, структура (количество резидентов) \\
\hline Иркутск & $\begin{array}{l}\text { Технопарк Иркутского научно-исследовательского технического } \\
\text { университета (ИрНИТУ) бизнес-инкубатор ИрНИТУ, научные } \\
\text { подразделения } \text { Физико-технического института в составе } \\
\text { университета, корпоративный научно-исследовательский центр «ОАО } \\
\text { «Иркутскэнерго»-ИрГТУ», другие научно-производственные центры; } \\
\text { создано более } 30 \text { малых инновационных предприятий; сотрудничает с } \\
\text { Технопарком - Ангарская нефтехимическая компания, СИБ «Технолог» } \\
\text { (бизнес-инкубатор), работающий совместно с Ангарским НПЗ над } \\
\text { использованием тяжелых нефтяных остатков, ЗАО НПФ Восток-ТОР, } \\
\text { занятое в сфере технологий обслуживания и ремонта трубопроводов, }\end{array}$ \\
\hline Ангарск & $\begin{array}{l}\text { Ангарский технопарк: комплекс объектов недвижимости и технической } \\
\text { инфраструктуры для размещения производств, созданный в } 2009 \text { г. на } \\
\text { производственных площадях Ангарского электромеханического завода; } \\
4 \text { площадки - индустриальный парк «МАХіМАХ», индустриально- } \\
\text { логистический парк «Greenchannel», производственно-сырьевой парк } \\
\text { «Кючевой» и агропромышленный парк «Монастырская протока», среди } \\
\text { партнеров технопарка - НК «Роснефть»; среди предлагаемых новых } \\
\text { проектов - } 6 \text { проектов полимерного производства, а также производства } \\
\text { строительной продукции. }\end{array}$ \\
\hline
\end{tabular}

В стадии разработки проект «Байкальский центр биомедицинских исследований» (БайкалБиоМеда, ЦУР: направление 3 Обеспечение здорового образа жизни и содействие благополучию для всех в любом возрасте), инициаторы ИНЦ СО РАН и БНЦ СО РАН (табл. 3). Структура БайкалБиоМеда: 5 подразделений в Республики Бурятия, 4 - в городах Иркутск, Ангарск, 15 проектов на базе медицинских и учебных учреждений Иркутска. Планируется создать объединенную инфраструктуру Байкальского региона мирового уровня с привлечением стран-партнёров. Сотрудничество в рамках БайкалБиоМеда позволит рационально использовать ресурсы, создать условия для мобильности исследователей и специалистов, привлечения ведущих ученых к проведению исследований, обеспечение новых уровней взаимодействия исследовательских центров, организация стажировок и обучение специалистов в зарубежных центрах. 
Забориева Т. И., Гомбоев Б. О. Производственные, инфраструктурные и научнопроизводственные основания устойчивого развития Иркутской области

Таблица 3

Направления по продвижению устойчивого развития в Иркутской области в программно-стратегических документах

\begin{tabular}{|c|c|}
\hline $\begin{array}{l}\text { Проект стратегии СЭР: задачи, } \\
\text { в направлении устойчивого } \\
\text { развития }\end{array}$ & $\begin{array}{l}\text { Работа органов } \quad \text { государственной } \quad \text { власти } \\
\text { продвижению принципов «зеленой экономики» }\end{array}$ \\
\hline $\begin{array}{l}\text { 1) Формирование эффективной, } \\
\text { конкурентоспособной и эколо- } \\
\text { гически ориентированной моде- } \\
\text { ли развития. } \\
\text { 2) Обеспечение экологически } \\
\text { безопасного обращения с отхо- } \\
\text { дами, сокращение количества их } \\
\text { образования. } \\
\text { 3) Сохранение естественных } \\
\text { экологических систем, объек- } \\
\text { тов животного и растительного } \\
\text { мира. } \\
\text { 4) Охрана озера Байкал и защита } \\
\text { Байкальской природной терри- } \\
\text { тории от негативного воздей- } \\
\text { ствия антропогенных, техноген- } \\
\text { ных и природных факторов. }\end{array}$ & $\begin{array}{l}\text { - внедрение экологических критериев при принятии } \\
\text { решений о государственной поддержке (продвиже- } \\
\text { нии) инвестиционных проектов; } \\
\text { - стимулирование инвестиций, направленных на осу- } \\
\text { ществление модернизации и внедрение передовых } \\
\text { ресурсоэффективных и экологосберегающих техно- } \\
\text { логий, в том числе путем предоставления налоговых } \\
\text { преференций, компенсации процентной ставки по } \\
\text { кредитам финансовых организаций, прямого субси- } \\
\text { дирования, а также предоставления государственных } \\
\text { гарантий по кредитам; } \\
\text { - дестимулирование, вплоть до полного отказа, как в } \\
\text { случае с Байкальским целлюлозно-бумажным ком- } \\
\text { бинатом, экологически вредных производств, в том } \\
\text { числе путем ужесточения природоохраннного законо- } \\
\text { дательства, повышения объемов штрафов, введения } \\
\text { иных санкций за превышение установленных норм } \\
\text { выбросов загрязняющих веществ; } \\
\text { - создание специализированного экологического фон- } \\
\text { да, формируемого как за счет бюджетных, так и за счет } \\
\text { внебюджетных источников, средства которого будут } \\
\text { направляться на реализацию природоохранных меро- } \\
\text { приятий и ликвидацию последствий загрязнений; } \\
\text { - стимулирование создания мусоросортировочных и } \\
\text { мусороперерабатывающих комплексов на территории } \\
\text { региона, в том числе на условиях концессии. }\end{array}$ \\
\hline
\end{tabular}

Комплекс задач в Концепции направлен на улучшение состояния окружающей среды, снижение уровня отходов, их опасности, сохранение природных объектов. Выделены зоны опережающего развития и определена их специализация. (ЦУР: 9. Создание прочной инфраструктуры, содействие обеспечению всеохватной и устойчивой индустриализации и внедрению инноваций; ЦУР 11. Обеспечение открытости, безопасности, жизнестойкости и устойчивости городов и населенных пунктов):

1. Южная, с центром в г. Иркутске, со специализацией в развитии научнообразовательного комплекса, разработке инноваций и высокотехнологичных отраслей, таких как машиностроение и фармацевтика.

2. Северная, в зоне Байкало-Амурской магистрали, со специализацией в сфере добычи и первичной переработки природных ресурсов.

3. Прибайкальская - со специализацией в сфере туризма, рекреации и сопутствующих услуг. 
4. Сельхозориентированные районы области (в том числе юго-западные районы области, Усть-Ордынский бурятский округ) при сохранении существующей специализации в сфере агропромышленного комплекса.

\section{Заключение}

Конкурентные преимущества Иркутской области - крупные запасы природных ресурсов (газ, нефть, редкие металлы, железная руда, калийные соли, апатит и др., лесные, энергетические), срединное транспортно-географическое положение в России на Транссибе, относительно стран восточной и юговосточной Азии. Одним из основных приоритетов развития Иркутской области является комплексное развитие перерабатывающей промышленности на основе использования природных ресурсов, экологический туризм. Сложившаяся научнообразовательная база Иркутской области (институты Иркутского научного центра СО РАН, более 20 государственных и коммерческих ВУЗов, возрождающаяся сеть средних специальных обучающих образовательных организаций и др.) обеспечивают современный уровень развития конкретных программ и технических проектов, продвигая идеологию устойчивого развития.

Достижение поставленных в концептуально-стратегических разработках целей возможно на основе устойчивого и качественного развития экономики Иркутской области, и основным индикатором будет показатель стабилизация численности населения Иркутской области к 2030 г. как макромаркер благополучного вектора развития региона. Достижение стратегической цели стратегии подразумевает решение системы стратегических задач на принципах «зеленой» экономики, которые найдут отражение в конкретных планах социально-экономического развития муниципальных образований.

Драйвером экономики на принципах устойчивого развития являются новые организационные форматы научно-производственной деятельности - технопарки, научно-производственные кластеры в четырех выделенных зонах (Южная, Северная, Прибайкальская, Сельхозориентированные районы). Сотрудничество с соседними дальневосточными субъектами усилит положительные эффекты в социально-экономическом пространстве от преимуществ географического и природно-ресурсного потенциала Иркутской области на видимую перспективу.

\section{Литература}

1. География Сибири в начале XXI века. Т.3. Хозяйство и население. - Новосибирск: Академ. изд-во «Гео», 2014. - $251 \mathrm{c}$.

2. Дец И.А. Проектный подход в территориальном развитии: Байкальский регион / Отв. ред. Н.М. Сысоева; Рос. акад. наук, Сиб. отд-ние, Ин-т географии им. В.Б. Сочавы. Новосибирск: Академическое изд-во «Гео», 2018. - 139 с. - ISBN 978-5-6041445-0-3. DOI 10.21782/В978-5-6041445-0-3.

3. Зона Транссиба как евразийский экономический коридор / отв. ред. Л.М.Корытный. Иркутск: ИГ СО РАН, 2016. 251 с.

4. Ипполитова Н.А.Географические особенности добывающей промышленности Сибири.- Вестник Евразийской науки.- М.: Мир науки.- Т.10. №3.- 2018. 10с. DOI: 10.15862/85ECVN318 (http://dx.doi.org/10.15862/85ECVN318). 
Забориева Т. И., Гомбоев Б. О. Производственные, инфраструктурные и научнопроизводственные основания устойчивого развития Иркутской области

5. Инвестиционная стратегия Иркутской области на период до 2025 года www.invest. irkobl.ru/ru/Informaciya.../Investicionnaya-strategiya-Irkutskoj-oblasti

6. Концепция социально-экономического развития Иркутской области на период до 2020 года http://irkobl.ru/sites/economy/socio-economic/advance_planning/concept-ir.pdf

7. Народное хозяйство РСФСР в 1965 г. Статежегод / ЦСУ РСФСР. М.: Финансы и статистика, , 1966. 616 с.

8. Народное хозяйство РСФСР в 1977 г. Статежегод. / ЦСУ РСФСР. М.: Финансы и статистика, 1978. 343 с.

9. Народное хозяйство РСФСР в 1985 г. Статежегод / ЦСУ РСФСР. М. Финансы и статистика, 1986. 398 с.

10. Народное хозяйство РСФСР в 1987 г. Статежегод/ЦСУ РСФСР. М. Статистика, 1988. $600 \mathrm{c}$.

11. Нефтегазовый комплекс России 2017. Часть 1. Нефтяная промышленность 2017: долгосрочные тенденции и современное состояние // Л.В. Эдер, И.В. Филимонова, В.Ю. Немов, И.В. Проворная, М.В. Мишенин, А.В. Комарова и др. / под ред. А.Э. Конторовича. Новосибирск: ИНГГ СО РАН, 2018. 86 с.

12. Проект стратегии социально-экономического развития Иркутской области на период до 2030 года http://economy.gov.ru/minec/activity/sections/strategterplanning/.../ stsubject/.../2016021102.

13. URL: http://irkutskoil.ru/gas/

14. Регионы России. Социально-экономические показатели. Статистический сборник. T.1. 2000. М., 2000. 604 c.

15. Регионы России. Социально-экономические показатели. Статистический сборник. 2012. М., 2012. 990 с.

16. Регионы России: Социально-экономические показатели.2016: Стат. Сб./Росстат. M., 2016. -1326 c.

17. Регионы России: Социально-экономические показатели.2017: Стат. Сб./Росстат. M., 2017. -1402 c.

18. Регионы России: Основные социально-экономические показатели. 2016: Стат. Сб./ Росстат. М., 2017. -442 с.

19. Экономический коридор «Китай-Монголия-Росссия»: географические и экологические факторы и возможности территориального развития / Тезисы межд.геогр. конф. (Иркутск, 20-26 августа 2018 г.). Иркутск: ИГ СО РАН, 2018. 306 с.

\section{PRODUCTION, INFRASTRUCTURAL, SCIENTIFIC AND INDUSTRIAL BASES OF SUSTAINABLE DEVELOPMENT OF THE IRKUTSK REGION}

\section{T. I. Zabortseva, B. O. Gomboev}

(C) Tatiana Ivanovna Zabortseva

Dr. Sci. (Geogr.), Institute of Geography SB RAS, Russian Federation, Irkutsk 664033, Ulan-Batorskaya Str., 1

Irkutsk State University

E-mail: zabti@irigs.irk.ru 
(C) Bair Octyabrevich Gomboev

Dr. Sci. (Geogr.), Baikal Institute of Nature Management SB RAS, Russia, Ulan-Ude 670047, Sakhyanova st., 8

Buryat state university

24a, Smolin str., Ulan-Ude, 670000, Russia

E-mail: bgom@binm.ru

The article discusses the production, infrastructure and scientific-industrial bases of sustainable development of the Irkutsk region, as one of the supporting economic territories of Siberia. It is shown that the competitive advantages of the Irkutsk region consist in the presence of large reserves of natural resources (gas, oil, rare metals, iron ore, potash salts, apatite, etc., forest, energy), the middle transport and geographical position in Russia on Transsib, relative proximity to the countries of East and Southeast Asia. It has been determined that one of the main priorities of the development of the Irkutsk Region is the integrated development of the processing industry based on the use of natural resources, ecological tourism. The existing scientific and educational base of the Irkutsk Region (institutes of the Irkutsk Scientific Center of the SB RAS, more than 20 state and commercial universities, a reviving network of specialized secondary educational institutions, etc.) are designed to ensure the current level of development of specific programs and technical projects, promoting the ideology of sustainable development. The UN Sustainable Development Goals 2030 are considered in relation to the programs of socio-economic development of the Irkutsk region and the prerequisites for their implementation in the territory under consideration are shown.

Keywords. Natural resource potential, industrial development, transport and communication function, sustainable development goals, research and production activities. 